\title{
Evidence-based monitoring and evaluation of the faith-based approach to HIV prevention among Christian and Muslim youth in Wakiso district in Uganda
}

*Kagimu $\mathrm{M}^{1,2,3}$, Kaye $\mathrm{S}^{1,5}$, Ainomugisha $\mathrm{D}^{1}$, Lutalo I ${ }^{5}$, Walakira $\mathrm{Y}^{1}$, Guwatudde $\mathrm{D}^{2}$, Rwabukwali $\mathrm{C}^{4}$

1. Islamic Medical Association of Uganda

2. Makerere University School of Public Health

3. Department of Medicine, Makerere University College of Health Sciences.

4. Department of Sociology, Makerere University

5. Makerere University School of Public Health - CDC/HIV/AIDS Fellowship Program

\begin{abstract}
Background: The Islamic Medical Association of Uganda, has been implementing the faith-based approach to HIV prevention without baseline data on expected positive outcomes.

Objectives: To establish evidence-based baseline data on expected positive outcomes of the faith-based approach to HIV prevention.

Methods: A cross-sectional study of 15-24 year-old youths was analyzed for significant associations between HIV infections, risky behaviors, and religiosity.

Results: HIV prevalence was 3.6\% among Christians and 2.4\% among Muslims. Abstaining from sex among teenagers was at $54 \%$ for Christians and 58\% for Muslims. Being faithful in marriage among males was at $41 \%$ for Christians and $34 \%$ for Muslims and among females it was 65\% for Christians and 69\% for Muslims. Praying privately was associated with lower HIV infections and was observed among $60 \%$ of Christians. Sujda, the hyperpigmented marker of regular prayers on the forehead of Muslims was associated with lower HIV infections and observed in $42 \%$ of them. Ever drank alcohol was associated with higher HIV prevalence and observed in $52 \%$ of Christians and 17\% of Muslims. Male circumcision rates were $15 \%$ for Christians and $98 \%$ for Muslims.

Conclusion: A sero-behavioral-religiosity survey can provide evidence-based data for monitoring and evaluation of the faith-based approach to HIV prevention.

Key words: Evidence-based, monitoring and evaluation, faith-based approach, HIV prevention, Muslims, Christians. African Health Sciences 2012; 12(2): 119 - 128 http://dx.doi.org/10.4314/ahs.v12i2.7
\end{abstract}

\section{Introduction}

Uganda still has a high HIV prevalence of $6.4 \%$ and a high rate of new HIV infections which were estimated to be 135, 000 in 2005'. In Uganda's National HIV/AIDS Strategic Plan 2007/8 - 2011/ 12, the goal of HIV prevention is to reduce the incidence rate of HIV by $40 \%$ by the year 2012. In order to achieve this, one of the strategic actions is to promote $\mathrm{ABC}+$ - which includes: Abstinence, Being Faithful, and Condom use with risky sexual

\begin{tabular}{|l|}
\hline *Corresponding author: \\
Magid Kagimu \\
Associate Professor \\
Department of Medicine \\
Makerere University College of Health Sciences and \\
Chairman Islamic Medical Association of Uganda \\
P.O.Box 2773 \\
Kampala, Uganda \\
Telephone: 256-782-016868 \\
Email:mmkagimu@,utlonline.co.ug \\
imau@utlonline.co.ug
\end{tabular}

African Health Sciences Vol 12 No 2 June 2012 encounters. Another strategic action is to utilize religious institutions for the delivery of HIV prevention messages ${ }^{2}$. Faith-based organizations are recognized promoters of abstinence and faithfulness in marriage as a means of HIV prevention. They do this by using their faith teachings that encourage these supportive behaviors ${ }^{3,4}$. These faith teachings are intended to increase religiosity within the target communities.

The Islamic Medical Association of Uganda (IMAU) is one of the faith-based organizations that has been promoting the faith-based approach to HIV prevention among Muslim and Christian communities. In this approach, Muslim and Christian religious leaders were trained to educate their communities using a curriculum with scientific information supported by religious teachings from the Holy Qur'an and Holy Bible ${ }^{5}$. The faith based approach to HIV/AIDS has five pillars:

1. Believing in God 
2. Acquiring scientific knowledge about HIV/AIDS

3. Making use of relevant faith teachings and practices

4. Forming partnerships with and making use of religious leaders and their administrative structures.

5. Making use of the concept of self-control (struggle of the soul against temptation) by each individual to combat AIDS.

The expected positive outcomes of the five pillar faith-based approach to HIV/AIDS are:

1. Increase in religiosity among target communities

2. Increase in behaviors supportive of HIV prevention especially abstaining from sex and being faithful in marriage.

3. Reduction in new HIV infections in the community.

Examples of the faith teachings from the Holy Qur'an and Holy Bible used in the curriculum to promote Abstinence and Being faithful in marriage for HIV prevention are as follows:

\section{A. Holy Qur'an}

Nor come near to adultery: for it is a shameful deed and an evil, opening the road to other evils. (Holy Qur'an 17: 32. Translated by Abdullab Yusuf Ali).

\section{Relationship of the Islamic teaching to HIV prevention}

People should not indulge in anything that stimulates their sexual desires to commit adultery. If one commits adultery it is a shameful act and an evil because it may result in getting HIV infection.

The believers must eventually win through; those who bumble themselves in their prayers, who avoid vain talk, who are active in deeds of charity, who abstain from sex, except with those joined to them in the marriage bond ....... Holy Qur'an 23: 1-6. Translated by Abdullah Yusuf Ali).

The believers in Allah's guidance will eventually win in preventing HIV infection if they abstain from sex except to those married to them. This means that both men and women abstain from sex before marriage in which case they remain HIV negative and when they get married they only have sex with their HIV negative marital partners. This assumes that they do not get HIV infection from other routes such as HIV contaminated blood transfusion, getting pierced by HIV contaminated instruments, and through mother to child HIV transmission which may occur in a minority of cases who may have followed the Islamic teachings.

\section{B. Holy Bible}

You have heard that it was said, "Do not commit adultery". But now I tell you: anyone who looks at a woman and wants to possess her is guilty of committing adultery with her in his heart. So if your right eye causes you to sin, take it out and throw it away! It is much better for you to lose a part of your body than to have your whole body thrown into hell. If your right hand causes you to sin cut it off and throw it away! It is much better for you to lose one of your limbs than for your whole body to go to hell.

It was also said, "Anyone who divorces his wife must give her a written notice of divorce". But now I tell you: if a man divorces his wife, for any cause other than unfaithfulness, then he is guilty of making her commit adultery if she marries again, and the man who marries her commits adultery also. (Holy Bible, New Testament, Matthew 5: 27-32. Quoted from the Good News Bible published by the United Bible Societies).

\section{Relationship of Christian teaching to HIV prevention}

People should not indulge in activities that stimulate their sexual desires to commit adultery such as looking lustfully at women. If they do so they would eventually commit adultery which may result in HIV infection. People should struggle to keep their marriages so that they minimize chances of getting and spreading infections such as HIV.

The IMAU has been using this faith-based approach to HIV/AIDS prevention for Muslim and Christian communities in Wakiso district since 2005. However, IMAU had no baseline data on expected positive outcomes upon which to base future monitoring and evaluation. It is recommended that surveys with both serological and behavioral components should be institutionalized and conducted every 2-3 years in order to improve data availability so that evidence-based planning and decision making can be made for HIV prevention interventions in the target communities ${ }^{1}$.

The objective of the study was to establish baseline data on expected positive outcomes of the faith-based approach to HIV prevention among Muslim and Christian communities in Wakiso district.

\section{Methods}

\section{Study setting}

The Islamic Medical Association of Uganda runs a hospital called Saidina Abubakar Islamic Hospital located at Wattuba, in Wakiso district, $14 \mathrm{~km}$ on Bombo road. The IMAU has been promoting the 
faith-based approach to HIV prevention for communities surrounding this hospital. A convenience sample of 30 mosques and 30 churches around the hospital were identified to participate in the study.

\section{Study design and measurement of religiosity}

This was a cross-sectional study. Religiosity was defined as the degree of adherence to religious practices and getting associated spiritual experiences. It was measured using a modified Brief Multidimensional Measure of Religiousness/ spirituality ${ }^{6}$. The dimensions of religiosity that were most significantly associated with lower HIV infections were identified. These significant dimensions were included among indicators for which baseline percentages were to be determined from the cross-sectional data. Other dimensions of religiosity which were not statistically significantly associated with HIV infections but were known to be associated with several behaviors supportive of HIV prevention were also included as baseline indicators.

\section{Assessment of socio-demographic characteristics and HIV-risk behaviors}

Questions on socio-demographic characteristics and relevant HIV-risk behaviors were included in the study instrument. The socio-demographic and behavioral factors that appeared to be driving the epidemic in the target communities were identified in data analysis. These were also included among the baseline indicators. The indicators on Abstinence and Being faithful in marriage were included because they are a special target for the faith-based approach to HIV prevention.

\section{Assessment of new HIV infections}

The prevalence of HIV in the 15-24 year age-group is a reasonable proxy indicator of new HIV infections ${ }^{7,8}$. The IMAU hospital staff performed home-based HIV counseling and testing targeting clients 15-24 years of age. They used rapid HIV testing kits following the recommendation of the Uganda Ministry of Health ?

\section{Results}

Between July and December 2010, 4268 clients aged 15-24 years were counseled and tested. There were 1224 Muslims and 2933 Christians. Because of different faith traditions, data analysis for Christians and Muslims was done separately. For example,
Christianity does not advocate for excessive alcohol consumption but alcohol drinking is not altogether forbidden. In contrast, alcohol drinking is forbidden in Islam. Another example is that in accordance with Islamic teachings, Muslim males are circumcised as part of their religious obligation. On the other hand, Christian males are not generally circumcised according to their faith tradition. Both alcohol consumption and lack of circumcision have been associated with higher HIV infection rates ${ }^{10}$.

\section{Christian respondents}

Socio-demographic characteristics, behavioral factors and social practices associated with HIV infections

Higher HIV infection rates were associated with being a young adult (odds ratio 4.65, 95\% CI 2.538.55, $\mathrm{p}<0.001$ ), never having attended school (odds ratio 5.13, 95\% CI 2.09-12.55, $\mathrm{p}<0.001)$ and being out of school (odds ratio 2.42, 95\% CI 1.46-4.00, $\mathrm{p}<0.001)$.

The behavioral factors associated with HIV infection included ever having sex (odds ratio 4.32, 95\% CI 2.09-8.94, $\mathrm{p}<0.001$ ), having multiple lifetime sexual partners (odds ratio 5.64, 95\% CI 2.05-15.51, $\mathrm{p}<0.001)$, multiple lifetime marital sexual partners (odds ratio 2.67, 95\% CI 1.16-6.11, $\mathrm{p}=0.016$ ) and ever having sex during menstruation (odds ratio 1.96, 95\% CI 1.23-3.12, $\mathrm{p}=0.004$ ).

HIV infections were also significantly associated with those who ever drank alcohol (odds ratio $2.40,95 \% \mathrm{CI} 1.56-3.69, \mathrm{p}<0.001)$, ever been drunk (odds ratio 1.97, 95\% CI 1.09-3.57, $\mathrm{p}=0.022$ ), drink nowadays (odds ratio 1.85, 95\% CI 1.14-3.00, $\mathrm{p}=0.011)$, and those who have ever taken alcohol before sex (odds ratio 2.99, 95\% CI 1.78-5.02, $\mathrm{p}<0.001)$. Those who have ever taken narcotic drugs for recreation were also more likely to have HIV infection (odds ratio 2.26, 95\% CI 1.18- 4.32, $\mathrm{p}=0.012)$.

Male circumcision is a practice that has been associated with lower HIV infections. It may be initiated by parents for their children or by the individual himself later in life. In our study, among male Christians who were circumcised $3(2 \%)$ were HIV positive and among the uncircumcised 42 (4\%) were HIV positive. The difference was not statistically significant. Among the circumcised Muslim males, $10(2 \%)$ were HIV positive and among the circumcised Christian males, $3(2 \%)$ were HIV positive. The difference was not statistically significant (odds ratio 1.16, 95\% CI 0.31-4.26, 
$\mathrm{p}=0.823)$. When all males were analyzed with Muslims and Christians combined, among those who were circumcised, 13 (2\%) were HIV positive and among the uncircumcised, 42 (4\%) were HIV positive. The difference was statistically significant (odds ratio 2.21, 95\% CI 1.17-4.14, $\mathrm{p}=0.012$ ). The majority of the circumcised HIV positive respondents (10 out of 13), were Muslims and all the 42 uncircumcised HIV positive respondents were Christians.

\section{Religiosity dimensions associated with HIV infections among christians}

The religiosity dimensions associated with HIV infections are shown in table 1. Religiosity dimensions were assessed as ordinal variables. For the purpose of comparison, respondents who reported the highest order of the dimension were categorized as having high religiosity for that dimension. Since there were very few respondents who reported the lowest orders of the religiosity dimensions, all other responses were categorized as moderate religiosity for the particular dimension under review.

Table 1: Religiosity dimensions associated with HIV infections among christians

\begin{tabular}{|c|c|c|c|c|c|}
\hline Dimension & $\begin{array}{l}\text { HIV Positive } \\
\text { n (\%) }\end{array}$ & $\begin{array}{l}\text { HIV Negative } \\
\text { n (\%) }\end{array}$ & Odds Ratio & 95\% C.I & p-value \\
\hline \multicolumn{6}{|c|}{ Ask for God's help amidst daily activities } \\
\hline High (many times a day) & $14(2)$ & $624(98)$ & & & \\
\hline Moderate & $92(4)$ & $2,192(96)$ & 1.87 & $1.06-3.31$ & 0.029 \\
\hline \multicolumn{6}{|c|}{ I feel guided by God amidst daily activities } \\
\hline High (many times a day) & $14(2)$ & 654(98) & & & \\
\hline Moderate & $92(4)$ & $2170(96)$ & 1.98 & $1.12-3.50$ & 0.017 \\
\hline \multicolumn{6}{|c|}{ I feel thankful for God's blessing } \\
\hline High (many times a day) & $18(2)$ & $806(98)$ & & & \\
\hline Moderate & $88(4)$ & $2017(96)$ & 1.95 & $1.17-3.27$ & 0.009 \\
\hline \multicolumn{6}{|l|}{ Praying privately } \\
\hline High (several times a day) & $51(3)$ & $1715(97)$ & & & \\
\hline Moderate & $54(5)$ & 1 104(95) & 1.64 & $1.11-2.43$ & 0.012 \\
\hline \multicolumn{6}{|l|}{ Trying hard to be patient } \\
\hline High (strongly agree) & $26(3)$ & $977(97)$ & & & \\
\hline Moderate & $80(4)$ & $1842(96)$ & 1.63 & $1.04-2.56$ & 0.031 \\
\hline \multicolumn{6}{|l|}{ Trying hard to love God } \\
\hline High (strongly agree) & $44(3)$ & $1489(97)$ & & & \\
\hline Moderate & $62(4)$ & $1331(96)$ & 1.58 & $1.06-2.34$ & 0.022 \\
\hline \multicolumn{6}{|l|}{ Parental existence } \\
\hline Both alive & $38(2)$ & $1542(98)$ & & & \\
\hline One or both dead & $68(5)$ & $1265(95)$ & 2.18 & $1.45-3.27$ & $<0.001$ \\
\hline
\end{tabular}

HIV infection rates were higher among those who did not ask for God's help amidst daily activities many times a day (odds ratio $1.87,95 \%$ CI 1.063.31, $\mathrm{p}=0.029)$, those who did not feel guided by God amidst daily activities many times a day (odds ratio $1.98,95 \%$ CI 1.12-3.50, $\mathrm{p}=0.017$ ) and those who did not feel thankful for God's blessings many times a day (odds ratio 1.95, 95\% CI 1.17-3.27, $\mathrm{p}=0.009)$. Those who did not pray privately several times a day had higher HIV infection rates (odds ratio $1.64,65 \% \mathrm{CI} 1.11-2.43, \mathrm{p}=0.012)$. The HIV infection rates were also higher among those who did not strongly agree that they tried hard to be patient in all their dealings with themselves and others according to their religious teachings (odds ratio 1.63, 95\% CI 1.04-2.56, $\mathrm{p}=0.031$ ), and those who did not strongly agree that they tried hard to love God with all their heart, mind and soul in accordance with their religious teachings (odds ratio 1.58, 95\% CI 1.06-2.34, $\mathrm{p}=0.022$ ).

Religiosity in young people is usually initiated and promoted by their parents ${ }^{11 .}$ Young respondents who had lost one or both parents were found to have higher HIV infection rates (odds ratio 2.18, 95\% CI 1.45-3.27, $\mathrm{p}<0.001)$. 
Behavioral factors and religiosity dimensions associated with age-group among christians

Abstaining from sex was more common among teenagers as expected (odds ratio 12.80, 95\% CI 10.13-16.19, $\mathrm{p}<0.001)$. Being faithful in marriage was more common among teenagers (odds ratio 1.91, $95 \%$ CI 1.30-2.80, $\mathrm{p}<0.001)$. Young adults were more likely to have multiple lifetime sexual partners (odds ratio 2.97, 95\% CI 2.33-3.78, p<0.001). Sex during menstruation was also more common among young adults (odds ratio 1.35, 95\% CI 1.02-1.79, $\mathrm{p}=0.037)$.

Drinking alcohol was more common among young adults. Young adults were more likely to have ever drank alcohol (odds ratio 3.47, 95\% CI 2.94-4.10, $\mathrm{p}<0.001$ ), ever been drunk (odds ratio 2.32, 95\% CI 1.80-2.98, $\mathrm{p}<0.001)$, to be drinking nowadays (odds ratio 2.28, 95\% CI 1.77-2.94, $\mathrm{p}<0.001)$ and to have ever taken alcohol before sex (odds ratio 2.76, 95\% CI 2.00-3.81, $\mathrm{p}<0.001$ ). Young adults were also more likely to have ever used narcotic drugs for recreation (odds ratio 2.36, 95\% CI 1.57$3.55, \mathrm{p}<0.001)$. Teenagers were more likely to wear a cross (odds ratio 1.57, 95\% CI 1.27-1.97, $\mathrm{p}<0.001$ ). It is also important to note that as expected teenagers were more likely to have both parents alive compared to young adults (odds ratio 1.85, 95\% CI 1.58-2.16, $\mathrm{p}<0.001)$.

Behavioral factors and religiosity dimensions associated with gender among christians

Females were more likely to abstain from sex (odds ratio $1.19,95 \%$ CI 1.01-1.41, $\mathrm{p}=0.039)$. Females were also more likely to be faithful in marriage (odds ratio 2.68, 95\% CI 2.07-3.47, $\mathrm{p}<0.001)$. Males were more likely to have multiple lifetime sexual partners (odds ratio $2.15,95 \%$ CI 1.71-2.70, $\mathrm{p}<0.001)$, multiple sexual partners outside marriage (odds ratio 1.97, 95\% CI 1.34- 2.87, $\mathrm{p}<0.001)$ and multiple lifetime marital sexual partners (odds ratio 1.96, 95\% CI 1.253.09, $\mathrm{p}=0.003)$.

Females were more likely to have ever had sex during menstruation (odds ratio 1.30, 95\% CI 1.04-1.62, $\mathrm{p}=0.021$ ). Alcohol drinking was more of a male affair. Males were more likely to have ever drank alcohol (odds ratio 1.60, 95\% CI 1.38-1.85, $\mathrm{p}<0.001$ ), ever been drunk (odds ratio 1.93, 95\% CI 1.54-2.41, $\mathrm{p}<0.001$ ), and to be drinking nowadays (odds ratio 1.74, 95\% CI 1.44-2.18, $\mathrm{p}<0.001$ ). Males were also more likely to have ever used narcotic drugs for recreation (odds ratio 5.52, 95\% CI 3.53-8.66, $\mathrm{p}<0.001)$

Females were more religious than males on several dimensions of religiosity that were analyzed. Females were more likely to pray privately away from the church (odds ratio 1.66, 95\% CI 1.43-1.94, $\mathrm{p}<0.001$ ), read the Bible more than once a day (odds ratio $1.67,95 \%$ CI 1.30-2.14, $\mathrm{p}<0.001$ ) and fast more than one month a year according to their religious tradition (odds ratio 1.41, 95\% CI 1.20-1.65, $\mathrm{p}<0.001)$. Females were also more likely to attend church more than once a week (odds ratio 1.42, 95\% CI 1.18-1.71, $\mathrm{p}<0.001$ ), and to wear a cross (odds ratio $1.36,95 \%$ CI $1.09-1.69, \mathrm{p}=0.006$ )

\section{Baseline sero-behavioral-religiosity indicators among christians}

The baseline serological, behavioral and religiosity indicators that were included in monitoring and evaluation of the faith-based approach to HIV prevention in the Christian communities are shown in table 2. They were derived from evidence obtained from the study.

Table 2: Baseline sero-behavioral-religiosity indicators among Christians

\begin{tabular}{llll}
\hline Indicator & \multicolumn{2}{l}{$\begin{array}{l}\text { Baseline } \\
\text { Percentage }\end{array}$} & $\begin{array}{l}\text { Indicator } \\
\text { Percentage }\end{array}$ \\
\hline $\begin{array}{l}\text { Serological Indicators } \\
\text { HIV infection }\end{array}$ & \multicolumn{2}{c}{ Drink nowadays } \\
Overall & 3.6 & Overall & \\
Males & 3.2 & Males & 50 \\
Females & 4.0 & Females & 56 \\
Behavioral Indicators & & Ever been drunk & 42 \\
Abstaining from sex: & & Overall & 70 \\
Overall & 25 & Males & 76 \\
Teenagers & 54 & Females & 62 \\
\hline
\end{tabular}


Continuation of table 2

\begin{tabular}{|c|c|c|c|}
\hline Indicator & $\begin{array}{l}\text { Baseline } \\
\text { Percentage }\end{array}$ & Indicator & $\begin{array}{l}\text { Baseline } \\
\text { Percentage }\end{array}$ \\
\hline Being faithful in marriage & & \multicolumn{2}{|l|}{ Ever taken alcohol before sex } \\
\hline Overall & 54 & Overall & 41 \\
\hline Males & 41 & Males & 42 \\
\hline Females & 65 & Females & 40 \\
\hline \multicolumn{2}{|l|}{ Condom use } & \multicolumn{2}{|c|}{ Ever used narcotic drugs for recreation } \\
\hline Ever used & 77 & Overall & 5 \\
\hline Condom use during last sex outside & 60 & Males & 9 \\
\hline \multirow{2}{*}{ marriage } & & Females & 2 \\
\hline & & Male circumcision & 15 \\
\hline \multicolumn{2}{|l|}{ Lifetime multiple sexual partners } & \multicolumn{2}{|l|}{ Religiosity Indicators } \\
\hline Overall & 81 & \multicolumn{2}{|l|}{ Daily spiritual experiences } \\
\hline Males & 86 & \multicolumn{2}{|c|}{ Asking for God's help in daily activities } \\
\hline \multirow[t]{5}{*}{ Females } & 75 & High - many times a day & 22 \\
\hline & & \multicolumn{2}{|c|}{ Feeling guided by God in daily activities } \\
\hline & & High - many times a day & 23 \\
\hline & & \multicolumn{2}{|l|}{ Feeling thankful for God's blessings } \\
\hline & & High - Many times a day & 28 \\
\hline \multicolumn{2}{|c|}{ Multiple sexual partners outside marriage } & \multicolumn{2}{|l|}{ Private religious practices } \\
\hline Overall & 57 & \multicolumn{2}{|c|}{ Praying privately other than at a church } \\
\hline Male & 63 & \multirow[t]{2}{*}{ High- Several times a day } & \multirow[t]{2}{*}{60} \\
\hline Female & 46 & & \\
\hline Lifetime marital sexual partners & & \multicolumn{2}{|l|}{ Religious commitment } \\
\hline Overall & 20 & \multirow{2}{*}{\multicolumn{2}{|c|}{$\begin{array}{l}\text { Trying hard to be patient in dealing with self } \\
\text { and other }\end{array}$}} \\
\hline Male & 17 & & \\
\hline \multirow[t]{10}{*}{ Female } & 16 & High- Strongly agree & 34 \\
\hline & & Trying hard tolove God & \\
\hline & & High- Strongly agree & 52 \\
\hline & & Bible reading & \\
\hline & & High - more than once a day & 10 \\
\hline & & \multicolumn{2}{|c|}{ Fasting according to religious tradition } \\
\hline & & High - more than 1 month per year & 32 \\
\hline & & \multicolumn{2}{|l|}{$\begin{array}{l}\text { High - more than } 1 \text { month per year } 32 \\
\text { Church attendance }\end{array}$} \\
\hline & & $\begin{array}{l}\text { High - More than once a week } \\
\text { Wearing a cross }\end{array}$ & 20 \\
\hline & & Yes & 15 \\
\hline \multicolumn{4}{|l|}{ Sex during menstruation } \\
\hline Overall & 18 & & \\
\hline Males & 17 & & \\
\hline Females & 21 & & \\
\hline \multicolumn{4}{|l|}{ Ever drank alcohol } \\
\hline Overall & 52 & & \\
\hline Males & 58 & & \\
\hline Females & 46 & & \\
\hline
\end{tabular}

\section{Baseline serological indicators}

These were derived from HIV prevalence segregated by gender. The overall HIV prevalence among Christian respondents was 3.6\%.
Baseline behavioral indicators

These were derived from indicators that were significantly associated with HIV infection in the study and were most likely to be driving the HIV epidemic. In addition, indicators of $\mathrm{ABC}+$ were included 
among the baseline indicators, because this is one of the national strategic actions for HIV prevention. In the population studied, only abstinence from sex was significantly associated with lower HIV infections. Condom use is not usually significantly promoted in the faith-based approach because it is thought to encourage sex outside marriage which goes against both Muslim and Christian faith teachings. However it was included among baseline indicators because the majority of the respondents had ever used condoms anyway.

Male circumcision was not significantly associated with lower HIV infection rates among the respondents studied. However, there were more HIV positive cases among the uncircumcised compared to the circumcised. Male circumcision was included among the baseline indicators because it is one of the national strategies for HIV prevention.

\section{Baseline religiosity indicators}

Baseline religiosity indicators were derived from dimensions of religiosity that were found to be significantly associated with HIV infection in the analysis of the data. Other religiosity dimensions that were significantly associated with behaviors supportive of HIV prevention such as church attendance and Bible reading were included although they were not significantly associated with HIV infections among the study respondents.

\section{Muslim respondents}

Socio-demographic factors, behavioral factors and religiosity dimensions associated with HIV infections

The socio-demographic and behavioral factors associated with HIV infection among Muslims are shown in table 3. Muslim respondents who ever drank alcohol, had a higher HIV infection rate (odds ratio 2.28, 95\% CI 1.02-5.10, $\mathrm{p}=0.038$ ). Muslim respondents who ever had sex during menstruation also had a higher HIV infection rate (odds ratio 2.57, 95\% CI 1.02-6.46, $\mathrm{p}=0.037$ ). Muslims who had lost one or both parents also had higher HIV infections (odds ratio 3.23, 95\% CI 1.44-7.23, $\mathrm{p}=0.003$ ). Muslims who had no Sujda, the hyperpigmented spot on the forehead as result of prostration during regular prayers, had a higher HIV infection rate compared to those with Sujda (odds ratio 2.74, 95\% CI 1.10-6.83, p=024). Muslims who fasted one month or less per year also had a higher HIV infection rate compared to those who fasted more frequently (odds ratio 2.46, 95\% CI 1.07-5.67, $\mathrm{p}=0.028$ ).

Table 3: Comparison of socio-demographic characteristics, behavioral factors and religiosity dimensions with HIV infection rates among Muslims

\begin{tabular}{|c|c|c|c|c|c|}
\hline $\begin{array}{l}\text { Characteristic } \\
\text { Gender }\end{array}$ & $\begin{array}{l}\text { HIV Positive } \\
\mathrm{n}(\%)\end{array}$ & $\begin{array}{l}\text { HIV Negative } \\
\mathrm{n}(\%)\end{array}$ & Odds ratio & $95 \% \mathrm{CI}$ & p-value \\
\hline Male & $11(2)$ & $602(98)$ & & & \\
\hline Female & $18(3)$ & $589(97)$ & 1.68 & $0.79-3.59$ & 0.177 \\
\hline \multicolumn{6}{|l|}{ Age } \\
\hline Teenagers $(15-19)$ & $9(2)$ & $486(98)$ & & & \\
\hline Young adults $(20-24)$ & $20(3)$ & 709 (97) & 1.53 & $0.69-3.39$ & 0.292 \\
\hline \multicolumn{6}{|l|}{ Marital status } \\
\hline Married & $0(0)$ & $67(100)$ & & & \\
\hline Cohabiting & $6(2)$ & $258(98)$ & 1.44 & $0.58-3.58$ & 0.427 \\
\hline Cohabiting & $6(2)$ & $306(98$ & & & \\
\hline Never been married & $23(3)$ & $813(97)$ & 1.44 & $0.58-3.58$ & 0.427 \\
\hline \multicolumn{6}{|c|}{ Ever had sex during menstruation } \\
\hline Yes & $7(5)$ & $123(95)$ & & & \\
\hline No & $15(2)$ & $678(98)$ & 2.57 & $1.02-6.46$ & 0.037 \\
\hline \multicolumn{6}{|l|}{ Ever drank alcohol } \\
\hline Yes & $9(4)$ & 193(96) & & & \\
\hline No & $20(2)$ & $980(98)$ & 2.28 & $1.02-5.10$ & 0.038 \\
\hline \multicolumn{6}{|l|}{ Fasting } \\
\hline High $(>1$ month per year) & $21(2)$ & $1,009(98)$ & & & \\
\hline Moderate & $8(5)$ & 156(95) & 2.46 & $1.07-5.67$ & 0.028 \\
\hline \multicolumn{6}{|l|}{ Sudja } \\
\hline Yes & $6(1)$ & 487(99) & & & \\
\hline No & $22(3)$ & 651(97) & 2.74 & $1.10-6.83$ & 0.024 \\
\hline \multicolumn{6}{|l|}{ Parental existence } \\
\hline Both alive & $9(1)$ & $720(99)$ & & & \\
\hline One or both dead & $19(4)$ & $470(94)$ & 3.23 & $1.44-7.23$ & 0.003 \\
\hline
\end{tabular}


Behavioral factors associated with age-group among Muslim respondents

Teenagers were more likely to be abstaining from sex as expected (odds ratio 16.78, 95\% CI 11.3624.83, $\mathrm{p}<0.001)$. Young adults were more likely to have ever used condoms (odds ratio 1.48, 95\% CI 1.03-2.13, $\mathrm{p}=0.032$ ), ever drank alcohol (odds ratio $1.78,95 \%$ CI 1.28-2.47, p<0.001), ever taken alcohol before sex (odds ratio 2.59, 95\% CI 1.10-6.10, $\mathrm{p}=0.024)$ and ever used narcotic drugs for recreation (odds ratio $2.79,95 \%$ CI 1.38-5.66, $\mathrm{p}=0.003$ ).

\section{Behavioral and religiosity factors associated} with gender among Muslim respondents

Females were more likely to be faithful in marriage (odds ratio 4.16, 95\% CI 2.72-6.38, $\mathrm{p}<0.001$ ). Males were more likely to have ever used narcotic drugs for recreation (odds ratio 9.48, 95\% CI 3.69-24.37, $\mathrm{p}<0.001)$. Muslim males were generally more religious than Muslim females on the dimensions of religiosity where significant associations were observed. Males were more likely to have Sujda, the hyperpigmented marker of prostration due to regular prayers found on the forehead of Muslims (odds ratio 1.27, 95\% CI 1.01-1.61, $\mathrm{p}=0.043$ ). Males were also more likely to attend mosque prayers compared to females (odds ratio 1.45, 95\% 1.15$1.83, \mathrm{p}=0.002)$.

\section{Baseline sero-behavioral-religiosity indicators for muslims}

The baseline sero-behavioral-religiosity indicators for Muslims in the target community are shown in table 4. The overall HIV prevalence among Muslim respondents was $2.4 \%$. The behavioral indicators include baseline percentages for $\mathrm{ABC}+$ which is a national strategy for HIV prevention. Religiosity indicators were derived from religiosity dimensions that were significantly associated with lower HIV infection rates in the study. The main significant indicators were Sujda and fasting. Other indicators were added which were known to be significantly associated with behaviors supportive of HIV prevention although they were not associated with lower HIV infections among the study respondents. These included males wearing a Muslim cap and females wearing a long dress (Hijab).
Table 4: Sero-behavioral-religiosity indicators for Muslims

\begin{tabular}{lc}
\hline Indicator & Baseline (\%) \\
\hline Serological: & \\
HIV infection & 2.4 \\
Overall & 1.8 \\
Males & 3.0 \\
Females & \\
Behavioral: & \\
Abstaining from sex & 28 \\
Overall & 58 \\
Teenagers & \\
Being faithful in marriage & 52 \\
Overall & 34 \\
Male & 69 \\
Female & \\
Condom use & 77 \\
Ever used & 64 \\
Condom used during last sex outside & \\
marriage & 17 \\
Ever drank alcohol & 4 \\
Ever used narcotics & 98 \\
Male circumcision & \\
Religiosity: & \\
Have Sujda & \\
Males wearing Muslim cap & 20 \\
Females wearing long dress (Hijab) & 39 \\
Mosque attendance & \\
High - More than once a week & 38 \\
Fasting & \\
High - More than one month a year & 86 \\
\hline
\end{tabular}

\section{Discussion}

The HIV prevalence among the 15-24 year-old respondents was lower compared to the national average of $6.4 \%$. This is consistent with what was documented in the 2005. Uganda sero-behavioral survey ${ }^{12}$. HIV prevalence was lower among Muslim respondents compared to Christian respondents. This is consistent with what other scholars have observed 12, ${ }^{13}$. The observed difference could be due to the higher rate of male circumcision among Muslims which reduces their risk of HIV infections. However, there may be other factors involved. When Christians who were circumcised were compared to uncircumcised Christians there was no statistically significant difference in HIV prevalence. This could have been due to the small numbers in the analysis. When Muslims were combined with Christians in the analysis, there was a significant difference in HIV prevalence rates between the circumcised and the 
uncircumcised. This could have been due to the larger numbers involved in the analysis. The alternative explanation could be that there are additional behaviors and practices that may lower HIV prevalence among the circumcised who were predominantly Muslims. These behaviors may include alcohol intake which was found to be lower among Muslims compared to Christians. This suggests that circumcision alone among both Christians and Muslims may only make a limited difference in reducing HIV prevalence if other risk factors are not reduced.

One limitation of our study was that the behavioral data were self-reported. It is possible that some respondents could have given socially desirable answers to some questions. This could result in underestimation or overestimation of the frequency of some behaviors depending on their social desirability. However, it is likely that this effect was minimal because the results were consist with what other researchers have noted. For example, the drivers of the epidemic in the community studied included multiple sexual partners, alcohol use, and narcotic drug use for recreation. This is consistent with what has been documented. ${ }^{1}$ HIV infections were significantly associated with respondents who have ever had sex during menstruation. This is consistent with what other researchers have noted. Sex during menstruation may result in a five-fold increase in the risk of a woman becoming HIVinfected by an HIV positive sexual partner. Men who engage in sexual intercourse with an HIV positive woman during menstruation are more than 3 times as likely to contact HIV compared to men with HIV positive partners who do not have sex during menstruation. The increased risks for men getting HIV infections when sex involves blood are due to the higher concentration of HIV in blood compared to that in the non-bloody genital secretions 14,15. Among Christian respondents, women were more religious and had fewer sexual partners outside marriage. This is consistent with what other researchers have observed ${ }^{16}$.

The baseline sero-behavioral and religiosity indicators were derived from the target community. They may be used in future sero-behavioral-religiosity surveys every 2-3 years to monitor and evaluate the status of the epidemic in the community. This is one of the recommendations in the Ugandan HIV prevention strategy ${ }^{1}$. Religious leaders may use the baseline indicators to plan their interventions and target the behavioral factors driving the epidemic in their communities. They may use faith teachings that discourage identified risky behaviors that are associated with HIV infection. They may also encourage religious behaviors and practices that were associated with lower HIV infections among the study respondents.

In future cross-sectional sero-behavioralreligiosity surveys to monitor and evaluate the status of the HIV epidemic in the target communities, it will be difficult to attribute any changes to any particular intervention. This is a well recognized problem $^{17}$. If there are improvements in the indicators, the best that may be noted is that the faithbased approach to HIV prevention could have contributed to the positive outcomes. More rigorous study designs such as cohort studies or randomized community intervention trials would have to be done to make firm statements about the cause of any observed changes ${ }^{18}$. More studies also need to be done to assess how HIV affects religiosity. Some studies have shown that those with HIV report greater use of religion and spirituality when compared with similar HIV-negative individuals ${ }^{19}$. It is also important to find out if different Muslim and Christian thinking affects the relationship between HIV and religiosity. For example, it would be interesting to find out if "Conservative" or "Fundamentalist" Christians or Muslims differ from the "Moderate" ones regarding the interaction between HIV and religiosity.

\section{Conclusion}

A sero-behavioral-religiosity survey can provide evidence-based data which can be used to monitor and evaluate the faith-based approach to HIV/AIDS prevention. However, there are limitations to attributing any observed future improvements in the baseline indicators to any one intervention.

\section{Acknowledgements}

We are grateful to the communities in Wakiso district who participated in this study.

We would also like to thank all the staff of Saidina Abubakar Islamic Hospital who participated in data collection, entry and analysis for the study. The support given to us by Prof. David Serwadda, Mr. Joseph Matovu and Dr. Rhoda Wanyenze of Makerere University School of Public Health- CDC/ HIV/AIDS Fellowship program is very much appreciated. 


\section{References}

1. Uganda AIDS Commission 2009. HIV Prevention Response and Modes of Transmission Analysis.

2. Uganda AIDS Commission (2007). Moving towards Universal Access: National HIV/AIDS Strategic Plan 2007/8-2011/12. Uganda AIDS Commission, Republic of Uganda.

3. Editorial. Faith-based approaches to HIV/ AIDS. AIDS Action. 2000; 49: 1-8.

4. Green E. Faith-based organizations: Contribution to HIV Prevention. 2003: U.S. Agency for International Development.

5. Islamic Medical Association of Uganda Faithbased approach to HIV/AIDS: Enhancing the community response. Training guidelines for religious leaders, community educators and the communities 2007. Available at www.imauuganda.org under downloads (Accessed on 25 November 2011).

6. Fetzer Institute, National Institute on Aging working group. Multidimensional measurement of religiousness/spirituality for use in health research. The John Fetzer Institute Michigan 2003. Available at www.fetzer.org under research (Accessed on 25 November 2011).

7. Rehle T, Saidel T, Mills S, Magnan R. Evaluating programs for HIV/AIDS prevention and care in developing countries. A handbook for program managers and decision makers. 2001 Family Health International, USAID.

8. Bertozzi S, Laga M, Bautista-Arredondo, Coutinho A. Making HIV Prevention programmes work. Lancet 2008; 372:831-844.

9. Uganda Ministry of Health 2005. HIV Counseling and Testing. A National Counsellor Training Manual.

10. The Institute of Global Engagement - IGE. Religion and HIV/AIDS in Nigeria. 2006.
Available at www.globalengage.org/media/ article.aspx?id=2034 (Accessed on 25 November 2011).

11. Merril RM, Salazar RD, Gardner NW. Relationship between family religiosity and drug use behavior among youth. Social Bebaviour and Personality. 2001; 29:347-357.

12. Ministry of Health $(\mathrm{MOH})$ Uganda and ORC Macro 2006. Uganda HIV/AIDS serobehavioral survey 2004-2005. Calverton Maryland USA: Ministry of Health ORC Macro.

13. Velayati A, Bakayer V, Bahadori M, Tabatabaei S, Alaei A, Farahbood A, Masjedi M. Religious and cultural traits in HIV/AIDS epidemics in sub-Saharan Africa. Archives of Iranian Medicine. 2007; 10(4): 486-497

14. Royce R, Sena A, Cates W, Cohen M. Sexual transmission of HIV. New England Journal of Medicine. 1997; 336:1072-1078.

15. Kalichman SC, Simbayi LC. Sex during genital bleeding and risks for HIV infection. Preliminary study of sexually transmitted clinic patients in Cape Town, South Africa. African Journal of AIDS Research. 2004; 3(1): 51-55.

16. Koenig HG, McCullough ME, Larson DB. Handbook of religion and health. Oxford University press 2001.

17. Parkhurst J. "What worked?" : The evidence challenges in determining the causes of HIV prevalence decline. AIDS Education and Prevention. 2008; 20 (3); 275-283.

18. Beaglehole R, Bonita R, Kjellstrom T. Basic epidemiology. World Health Organization. 1993.

19. Pargament KI, McCarthy S, Shah P, Ano G, Tarakeshwar N, Wachholtz A, Sirrine N, Vasconcelles E, Murray-Swank N, Locher A, Duggan J. Religion and HIV: a review of the Literature and Clinical Implications. Southern Medical Journal. 2004; 97 (12): 1201-1209. 